\title{
Pros and cons of centralization
}

A proposal by Germany's science minister to concentrate power over much of the country's best research is less monstrous than some are suggesting, but still leaves plenty to worry about.

ew countries have as much power vested in regional states as Germany. This federalism was a response to the centralization of power and 'Germanization' of education, science and art that occurred under National Socialism in the 1930s. In science and education, as in many other areas, this federalism has created a complicated system in which the responsibilities of the federal government and the 16 Länder (state) governments are intricately interwoven — too complicated to function efficiently. In a bid to revitalize the crisis-ridden country, the German government now plans to simplify matters.

Germany's research minister, Edelgard Bulmahn, may have sensed a political opportunity. Lacking profile in the cabinet, she needs a success. She wants to centralize funding of the Max Planck Society and the DFG, Germany's main research funding agency, while giving the Länder full financial responsibility both for university infrastructure and for non-university research carried out under the umbrella of the Leibniz Association. Her ideas have received a hostile reception from researchers (see page 790 in this issue).

But Germany's research managers are dismissing the idea too hastily. They say that centrally funded basic research could become overly biased towards political and strategic objectives. However, the world is full of successful examples of such centralized structures, in which funding agencies are nevertheless protected from direct political control. Indeed, a streamlining of the federal research system's cumbersome decision-making procedures is long overdue.

Giving the Länder full responsibility for universities, for example, would allow them to find solutions that better match local needs and requirements. This would be a vast improvement over the existing system, in which each new X-ray machine or building project that is backed by the Länder must also be approved at a federal level.

But maintaining and renewing university infrastructure is a costly and thankless task. The federal government's joint responsibility has a regulating effect, keeping in check the disparities in the quality of universities' research. Germany's science system would benefit if the universities were forced to rethink their strengths and weaknesses, and develop more distinctive profiles. The introduction of tuition fees could also support these efforts.

There are pitfalls to be avoided, however. True, the Länder have a vital interest in maintaining universities, just as they have in building and maintaining schools, regional roads and parks. But they would be less enthusiastic about the rest of the legacy. In particular, most Leibniz institutes have little or no regional linkage, so why should the state of Brandenburg, for example, be interested in funding the Leibniz institutes of astrophysics and climate research in its capital, Potsdam? What is to stop it closing these laboratories?

The Leibniz institutes are the least known and most diverse pillar of German research. Bulmahn's proposals are in effect a policy of abandonment that risks eroding Germany's arduously restructured research landscape. Perhaps the best Leibniz laboratories can find a new home at government-funded national research centres, or in the Fraunhofer Society for applied research?

Although more sensible than research managers would like to admit, Bulmahn's proposed reforms have put her out on a limb. In their current form, they might result in a cutback of overall research expenditure, the very opposite of the German government's declared goal. But with more thought and much fine-tuning, the reforms could be good for German research.

\section{Silence of the neuroengineers}

\section{Researchers funded by a defence agency should stop skirting the ethical issues involved.}

$\mathrm{N}$ euroengineering is in its infancy, but already provides plenty of food for thought. Ethicists can cite a slew of projects that they have studied while trying to come to grips with the new technology. How will it affect human identity, for example? And could it one day be used to control thought processes?

Not so long ago, the idea of connecting a tiny machine to the nerves of the heart had ethicists worried - would it make us in some way less human? Today, over half a million pacemakers are implanted annually without any soul searching. As with many new technologies, the reality turned out to less disturbing than some had speculated.

Integrating machines with the brain will be more ethically complex. One research group has shown how to control the movement of a rat by sending signals to electrodes implanted in its brain. Others have taught a monkey to control a robot arm using signals taken directly from its brain (see page 796). The scientists involved are happy to speculate about their work; some say that the robot-arm experiments, for instance, could lead to a new generation of prostheticlimbs.

But the researchers should perhaps spend more time pondering the intentions of the people who fund their work. A significant amount of US neuroengineering research is funded by the military through the US Defense Advanced Research Projects Agency (DARPA). The agency wants to create systems that could relay messages, such as images and sounds, between human brains and machines, or even from human to human.

In the long term, military personnel could receive commands via electrodes implanted in their brains. They could also be wired directly into the equipment they control. Do neuroengineers support these goals? Their research could make it happen, so they have a duty to discuss their opinions, and to answer questions from those who object to the development of such technologies. Yet when Nature talked to DARPA-funded neuroscientists, many were reluctant to debate the potential military uses of the technology, saying that the agency's goal of brain-machine interfaces was still many years off.

The agency's goal may indeed be a distant one. But like all new potential technologies, it is worth discussing the consequences now. Simply taking DARPA's money, and citing possible medical benefits, is not enough. The discussions may never achieve a consensus, but will achieve a better quality and balance with researchers' engagement. 